CONGENITAL HEART DISEASE

\title{
Pregnancy, fertility, and recurrence risk in corrected tetralogy of Fallot
}

\author{
J M Meijer, P G Pieper, W Drenthen, A A Voors, J W Roos-Hesselink, A P J van Dijk, B J M Mulder, \\ T Ebels, D J van Veldhuisen
}

Heart 2005;91:801-805. doi: 10.1136/hrt.2004.034108

See end of article for authors' affiliations

....................

Correspondence to: Dr Prof Dirk J van

Veldhuisen, Department of Cardiology, Thoraxcentre, University Hospital Groningen, PO Box 30 001,9700 RB Groningen, Netherlands; d.j.van. veldhuisen@thorax.azg.nl

Accepted 13 July 2004
Objective: To determine in women with surgically corrected tetralogy of Fallot the risk of pregnancy for mother and fetus, whether fertility was compromised, and the recurrence risk of congenital heart disease. Design: Data were collected from 83 patients through interviews and review of medical records. Results: In 29 patients 63 pregnancies were observed, of which 13 ended in an abortion. Fifty successful pregnancies were observed in 26 patients. During six successful pregnancies (12\%) complications (symptomatic right sided heart failure, arrhythmias, or both) occurred. Both patients who developed symptomatic heart failure had severe pulmonary regurgitation. No clear relation between offspring mortality, premature birth or being small for gestational age, and cardiac characteristics of the mother was identified. Fifty seven patients were childless (41 (72\%) voluntarily). Recurrence risk for congenital heart disease was $2.2 \%$. Infertility was uncommon.

Conclusions: Although complications did occur in five of $26(19 \%)$ of the patients with a corrected tetralogy of Fallot, pregnancy was generally well tolerated in this largest report so far. No obvious predictors for maternal events or child outcome were determined, except for a possible relation between severe pulmonary regurgitation and symptomatic heart failure.
$\mathrm{T}$ etralogy of Fallot is characterised by a ventricular septal defect with an overriding aorta and anterior deviation of the outlet septum, creating pulmonary stenosis and resulting in right ventricular hypertrophy. In developed countries tetralogy of Fallot has been corrected surgically in almost all patients. Before the 1960s surgical procedures were performed in older children, while nowadays almost all cases of tetralogy of Fallot are corrected during infancy. Pulmonary valves and right ventricular outflow tracts are often enlarged surgically by insertion of transannular patches, rendering the pulmonary valves incompetent. Survival rates of $85 \%$ and $86 \%$ have been reported at 32-36 years. ${ }^{1-3}$ Although patients with corrected tetralogy of Fallot achieve a good quality of life, late complications do occur in $10-15 \%$ at 20 years after the initial repair, of which the most important are right sided heart failure caused by pulmonary regurgitation and supraventricular or ventricular arrhythmia. ${ }^{145}$

Residual cardiac defects in combination with the circulatory changes observed during pregnancy (increased cardiac output and reduced systemic vascular resistance and blood pressure) may affect pregnancy in women with corrected tetralogy of Fallot. Heart failure and arrhythmia may therefore become manifest during pregnancy. ${ }^{6}$ In previous studies with small sample sizes, no serious complications have been reported. This study aimed primarily at establishing the risk of pregnancy for both mother and fetus in a larger cohort. Secondary objectives were to determine whether fertility was compromised and to determine the risk of congenital heart disease in the offspring.

\section{PATIENTS AND METHODS}

The CONCOR (CONgenital COR vitia) database is a Dutch national registry of patients with congenital heart disease, founded by the Netherlands Heart Foundation, that started to enrol patients in 2001. Eighty three women with corrected tetralogy of Fallot aged between 17 and 45 years whose data were entered in CONCOR between 2001 and September 2003 were enrolled in this study. These patients received care in four Dutch tertiary medical centres. Written informed consent was obtained from all patients and all four centres received approval from their respective research ethics committees. Questionnaires were used to supplement the information available from the medical records.

Information about surgical procedures was extracted from the CONCOR database. For each patient information regarding infertility, spontaneous or elective abortions $(<16$ weeks of gestation), family history for congenital heart disease, and the cardiologist's advice on pregnancy was obtained. The childless patients were asked why they were childless and about their plans for having children.

For each successful pregnancy (a pregnancy that did not end in an abortion) detailed information concerning New York Heart Association (NYHA) class and maternal haemodynamic data including ultrasound data, cardiac events, obstetric status, delivery, and paediatric examination were collected before pregnancy ( $<6$ weeks), during the first, second and third trimesters, during delivery, and after pregnancy. The ultrasound information concerned valvar function, right ventricular pressure, ventricular dimensions, and ventricular function. Cardiac events were defined as any of the following: symptomatic heart failure, arrhythmia, angina pectoris, syncope, endocarditis, and thromboembolic complications (both lung and systemic). Arrhythmic events were defined as symptomatic rhythm disorders registered on an ECG or arrhythmias needing treatment.

We reviewed the relation between deterioration of maternal characteristics (increasing NYHA class, worsening of right sided valvar disease, increasing right systolic ventricular pressure, worsening right ventricular function) and occurrence of cardiac complications during pregnancy, and the numbers of children who died within the first year of life,

Abbreviations: CONCOR, CONgenital COR vitia; NYHA, New York Heart Association 


\begin{tabular}{|c|c|c|}
\hline & $\begin{array}{l}\text { Total } \\
\text { population } \\
(n=83)\end{array}$ & $\begin{array}{l}\text { Patients with } \\
\text { successful } \\
\text { pregnancies }(n=26)\end{array}$ \\
\hline Age at inclusion (years) & $28.7(6.70)$ & NA \\
\hline Age at repair (years) & $4.4(3.8)$ & NA \\
\hline Age at pregnancy (years) & NA & $28.4(4.42)$ \\
\hline \multicolumn{3}{|l|}{ Surgeries before or after repair } \\
\hline Blalock Taussig shunt & $11 \%$ & $4 \%$ \\
\hline Waterston shunt & $21 \%$ & $31 \%$ \\
\hline RV oufflow tract procedure & $13 \%$ & $23 \%$ \\
\hline Pulmonary valve replacement & $17 \%$ & $19 \%$ \\
\hline \multicolumn{3}{|l|}{ Residual defects } \\
\hline Tricuspid regurgitation & $33 \%$ & $42 \%$ \\
\hline Pulmonary stenosis & $35 \%$ & $46 \%$ \\
\hline Pulmonary regurgitation & $87 \%$ & $85 \%$ \\
\hline Ventricular septal defect & $19 \%$ & $39 \%$ \\
\hline Co-morbidity & $22(26.5 \%)$ & NA \\
\hline Mental disability & $6(27.3 \%)$ & NA \\
\hline Gynaecological & $4(18.2 \%)$ & NA \\
\hline Scoliosis & $4(18.2 \%)$ & NA \\
\hline Various & $8(36.4 \%)$ & NA \\
\hline Fertility problems & $5(6.0 \%)$ & NA \\
\hline \multicolumn{2}{|c|}{ NYHA class I before first pregnancyNA } & $100 \%$ \\
\hline
\end{tabular}

who were small for gestational age, and who were born prematurely (between 16-37 weeks of gestation).

\section{RESULTS}

Table 1 presents baseline characteristics of the 83 female patients (between 17-45 years of age) who were enrolled in this study. Fifty seven patients $(69 \%)$ were childless for various reasons (table 2). Sixty three pregnancies were observed in 29 patients, of which 13 ended in abortion (one elective). Fifty successful pregnancies were observed in 26 patients, for a mean of 1.9 pregnancies for each patient. Six patients had one child, 10 patients had two children, four patients had three children, and two patients had four children. Four of these patients were pregnant at the time of enrolment. None of the women died.

All patients with successful pregnancies discussed pregnancy with their cardiologist and none of them had been advised against pregnancy. In the childless group (57 patients) one patient, who was mentally disabled, was negatively advised, 38 patients were not given negative advice, and 18 patients never discussed possible pregnancy with their cardiologist.

\section{Fertility}

Five patients reported fertility problems, of whom only one became pregnant after three unsuccessful in vitro fertilisation procedures and one intracytoplasmic sperm injection leading to pregnancy. Another patient, who tried in vitro fertilisation (once) and intracytoplasmic sperm injection (three times), remained childless despite one spontaneous miscarriage. In two patients a gynaecological explanation for the documented infertility was found.

\footnotetext{
Abortions

Patients without children reported three abortions, including one elective abortion for non-cardiac reasons. Four patients in the pregnant group reported 10 spontaneous abortions, of which nine occurred before 12 weeks of gestation. We found no relation between maternal characteristics (during their other successful pregnancies) of these four patients and these spontaneous abortions. Twelve abortions were spontaneous, which is $19 \%$ of 62 pregnancies (12 spontaneous abortions and 50 successful pregnancies).
}

\begin{tabular}{ll}
$\begin{array}{l}\text { Table } 2 \\
(\mathrm{n}=57)\end{array}$ & Reasons for not having children \\
\hline Childless by choice & $41(72.0 \%)$ \\
Mental disability & $6(10.5 \%)$ \\
Fear of possible maternal cardiac & $4(7.0 \%)$ \\
complications & $4(7.0 \%)$ \\
Fertility problems & $2(3.5 \%)^{*}$ \\
Co-morbidity & \\
\hline *Both had severe scoliosis. & \\
\hline
\end{tabular}

\section{Echocardiographic data}

In $92 \%$ of all 50 successful pregnancies cardiac ultrasound data were collected. Echocardiographic data from before pregnancy, during the first, second, and third trimesters, and after pregnancy were available for only $2 \%$ of the patients. Thus, for most pregnancies there were missing data at different time periods. Therefore, it was difficult to analyse these data properly. Nevertheless, table 3 describes the most important ultrasound data of the patients who developed complications.

\section{Cardiac maternal events}

Five (19\%) of the 26 patients with successful pregnancies developed complications during six pregnancies $(12 \%)$. Of these five patients mean (SD) age at repair was 6.8 (5.5) years, which is slightly higher than in the total group (4.4 years). All had arrhythmias and two also developed right sided heart failure (table 3). Three of these patients are described separately.

One patient (patient 3 in table 3 ) developed right sided heart failure and a supraventricular tachycardia, probably caused by severe pulmonary regurgitation, during the third trimester of her first pregnancy, for which she received diuretics and digitalis. Primary caesarean section had to be performed because of this cardiac maternal indication and a healthy child was born. The mother did not recover well after pregnancy and her pulmonary valve was replaced. During her second pregnancy she took disopyramide (antiarrhythmic drug) and no complications occurred. Patient 4 (table 3 ) also developed right sided heart failure, for which she received a diuretic. This pregnancy was further complicated by a breech presentation that resulted in a caesarean section. Shortly after delivery she had a supraventricular tachycardia, which required medication (sotalol). She recovered completely after delivery. Her child was too small for gestational age and later proved to be autistic. During 14 of 50 pregnancies $(28 \%), 10$ patients had severe pulmonary regurgitation; two of these patients are described above among the patients who developed symptomatic right sided heart failure.

The third patient (patient 2, table 3 ) with a medical history of arrhythmia discontinued the prescribed $\beta$ blocker according to protocol; however, this resulted in recurrence of the pre-existent tachycardia. Increased right ventricular systolic pressure $(85 \mathrm{~mm} \mathrm{Hg}$ ) was found in combination with only a mild pulmonary stenosis. No pulmonary hypertension existed but the diagnosis was multiple peripheral stenoses distal to the anastomotic conduit, which can explain the high right ventricular systolic pressure.

No other patients took drugs except for one, who received a calcium antagonist during her second pregnancy.

\section{Obstetric observations}

Table 4 summarises baseline characteristics of 46 deliveries. Caesarean section was performed 13 times (28\%). Five of these were maternal cardiac indications: three as a precaution; one for fear of recurrence of ventricular tachycardia; and one for heart failure. Few obstetric events occurred: one 
Table 3 Extensive overview of complications during pregnancy

\begin{tabular}{|c|c|c|c|c|c|c|}
\hline & \multicolumn{6}{|l|}{ Patient number } \\
\hline & 1 & 2 & 2 & 3 & 4 & 5 \\
\hline Pregnancy & 1 & 1 & 4 & 1 & 1 & 2 \\
\hline Total pregnancies & 1 & 4 & 4 & 2 & 1 & 2 \\
\hline \multicolumn{7}{|l|}{ Arrhythmia* } \\
\hline Type & $\mathrm{VT}$ & SVT & VT & SVT & SVT & $\mathrm{VT}$ \\
\hline Time of occurrence & $\mathrm{Tr} 1, \mathrm{Tr} 2$ & Tr2 & End of Trl & Tr3 & Shortly after delivery & After delivery \\
\hline Treatment & None & ECV & Metoprolol & Digitalis & Sotalol & Calcium antagonist \\
\hline Heart failure & No & No & No & Yes & Yes & No \\
\hline Time of occurrence & NA & NA & NA & Tr3 & Tr3 & NA \\
\hline Treatment & NA & NA & NA & Diuretics & Diuretics & NA \\
\hline Valve disease (right sided) & $\begin{array}{l}\text { Mild PR, mild TR, } \\
\text { mild PS }\end{array}$ & $\begin{array}{l}\text { Mild TR, } \\
\text { mild PS }\end{array}$ & & $\begin{array}{l}\text { Severe PR, } \\
\text { mild PS }\end{array}$ & Severe PR, mild PS & Mild PR, mild PS \\
\hline RV function & Reasonable & Normal & & Not known & $\begin{array}{l}\text { Normal in Tr1, } \\
\text { reasonable in Tr2 }\end{array}$ & Normal \\
\hline RV systolic pressure & $\begin{array}{l}\text { Increased } \\
(45 \mathrm{~mm} \mathrm{Hg})\end{array}$ & $\begin{array}{l}\text { Increased } \\
(85 \mathrm{~mm} \mathrm{Hg})\end{array}$ & & Not knownt & Not known & Not increased \\
\hline QRS duration (ms) & 140 & 120 & & 160 & 146 & 130 \\
\hline NYHA class decline & No & No & No & Yesł & Yes§ & No \\
\hline Child small for gestational age & No & Yes & Yes & No & Yes & No \\
\hline
\end{tabular}

pre-eclampsia; one premature rupture of membranes; and five blood transfusions for postpartum haemorrhage.

Table 5 summarises baseline characteristics of 46 children. Relations between deterioration of maternal characteristics and children who were small for gestational age, who were born prematurely, and who died within the first year of life were reviewed. The unexpected findings are described.

\section{Small for gestational age}

Eight children $(17 \%)$ of six different mothers were small for gestational age (birth weight $<10$ th centile). Only one of these mothers smoked (0-10 cigarettes a day) during pregnancy. Three children had the same mother: maternal complications occurred in her first and fourth pregnancy (patient 2, table 3). Another mother (patient 4, table 3) also developed complications. A fourth mother had NYHA class deterioration of one grade during the second trimester and increased right ventricular systolic pressure $(65 \mathrm{~mm} \mathrm{Hg})$. However, this patient had no complications during pregnancy.

\section{Premature birth}

Five children (11\%) were born prematurely (16-36 weeks) and no maternal complications were seen during these pregnancies. NYHA class declined during pregnancy in only one mother who gave birth prematurely: from NYHA class I before pregnancy to NYHA class III during the first trimester and to class II during the second and third trimesters. Afterwards she returned to class I.

\begin{tabular}{|c|c|}
\hline Pregnancy duration (weeks)* & $37.9(4.11)$, minimum 19 weeks \\
\hline $\begin{array}{l}\text { Premature births (defined as } \\
\text { 16-37 weeks) }\end{array}$ & 5 (11\%) (19-36 weeks) \\
\hline \multicolumn{2}{|l|}{ Delivery } \\
\hline Vaginal & $\begin{array}{l}33,1 \text { forceps and } 2 \text { vacuum for } \\
\text { non-cardiac reasons }\end{array}$ \\
\hline Primary caesarean section & 8 \\
\hline Secondary caesarean section & 5 \\
\hline \multicolumn{2}{|l|}{ Endocarditis prophylaxis given } \\
\hline Yes & $42(91 \%)$ \\
\hline No & $4(9 \%)$ \\
\hline
\end{tabular}

Death within the first year of life

Three children $(6.5 \%)$ died within the first year of life, one of them with a tetralogy of Fallot. He died at 10 months after birth. The other two children died of a non-cardiac reason; one child died shortly after a pregnancy duration of 23 weeks possibly due to an intrauterine infection. The other died at 19 weeks of gestation after induced labour. A chromosomal disorder (XXY; Klinefelter syndrome) was found by antenatal diagnostics, which was the reason for induced delivery. No significant correlation between maternal characteristics and these three children was found.

Forty $(87 \%)$ children were examined for the presence of congenital heart disease by fetal echocardiography. Two children $(4.3 \%)$ had congenital heart disease: one is the child with a tetralogy of Fallot described above and the other had trisomy 13 with several cardiac malformations and is still alive.

\section{DISCUSSION}

We describe 63 pregnancies, of which 50 were successful, in 29 women in a study population of 83 women with corrected tetralogy of Fallot. Therefore, this is the largest and most extensively documented series so far.

During pregnancy, important maternal cardiovascular haemodynamic changes occur. Until 32 weeks of gestation, cardiac output gradually increases to $140 \%$ by means of increasing heart rate and stroke volume. Thereafter cardiac output remains unchanged. Owing to a $20 \%$ reduction in systemic vascular resistance, blood pressure slightly decreases, reaching a minimum in mid-pregnancy. ${ }^{7-9}$ Two to six weeks post partum, cardiac output and heart rate return

Table 5 Baseline characteristics 46 children

\begin{tabular}{ll}
\hline Sex & \\
Boys & $28(61 \%)$ \\
Girls & $18(39 \%)$ \\
Birth weight $(\mathrm{g})^{*}$ & $3064(727.72) \dagger$ \\
Small for gestational age (<10th centile) & 8 children $(17 \%)$ \\
Died in utero & 0 \\
Died within 1 year after birth & $3(6.5 \%)$ \\
Recurrence risk of congenital heart disease & $2(4.3 \%)$ \\
\hline \multirow{2}{*}{ Mean (SD); $\dagger 49+$ th centile. } & \\
\end{tabular}


to pre-pregnancy levels. ${ }^{9}$ These physiological changes can exceed the functional reserve of a patient with congenital heart disease and lead to serious complications.

Several reports have described a total of 68 pregnancies in patients with a corrected tetralogy of Fallot..$^{10-14}$ No complications were reported in these 68 pregnancies, in contrast to our series.

In our study complications occurred during six pregnancies (12\%) in five patients (19\%). All five patients encountered arrhythmia further complicated by right sided heart failure in two pregnancies. During 14 pregnancies (28\%) severe pulmonary regurgitation was present, which led to complications in three pregnancies $(21 \%)$, including the two pregnancies of the patients with symptomatic heart failure. One of the patients, who developed right sided heart failure, had a second pregnancy, after pulmonary valve replacement, without complications. Therefore, pulmonary valve replacement before pregnancy may well be considered for patients with severe pulmonary regurgitation to prevent complications, although eight (57\%) of the patients with severe pulmonary regurgitation did not have complications during pregnancy. Maternal mortality was zero in this group.

In 1989, Nunley and colleagues ${ }^{15}$ described 208 patients with congenital heart disease who underwent cardiac surgery requiring extracorporeal circulation. ${ }^{15}$ The results suggest that the incidence of infertility is not higher among patients who have undergone cardiac surgery than in the general population. Nunley's group had only six patients with a tetralogy of Fallot of whom three never attempted to become pregnant. The other three patients had five successful pregnancies, with no fertility problems. ${ }^{15}$ In our study fertility does not seem to have been compromised in comparison with the general population. ${ }^{16}$

In our study $19 \%$ of the pregnancies ended in a spontaneous abortion, which is comparable with the incidence of $15 \%$ in the general population. ${ }^{17}$

A multifactorial aetiology is thought to be present in $85 \%$ of patients with congenital heart disease, including tetralogy of Fallot. ${ }^{18}$ In the general population the prevalence of congenital heart disease is $0.8 \%$ and prevalence of tetralogy of Fallot is $0.08 \%$. If one of the parents had a tetralogy of Fallot the recurrence risk for congenital heart disease ranged between $0.0-3.1 \%$ in various studies. ${ }^{19}{ }^{20}$ The recurrence risk was significantly higher if the mother had a congenital heart defect than if the father did. ${ }^{19}$

We observed congenital heart disease in two children, of whom one had trisomy 13. In trisomy 13 cardiac malformations occur in the majority of patients. ${ }^{21}$ So it is likely that this child's cardiac defects are related to the chromosomal disorder. Therefore, the recurrence risk for congenital heart disease, on the basis of the tetralogy of Fallot in the mother, was observed in this study to be one in 45 , which is $2.2 \%$ (excluding the child with trisomy 13).

Eight children $(17 \%)$ in this study were small for their gestational age (birth weight $<10$ th centile). The incidence of premature birth in the general population is $6-7 \%$; in this study the incidence was $11 \%$. Neither small size for gestational age nor premature birth was found to be related to maternal characteristics.

Three children $(6.5 \%)$ died during their first year of life. Therefore, the incidence in our study population is significantly higher than the observed $0.5 \%$ in the normal Dutch population.[22] However, we found no obvious relation with maternal characteristics.

Caesarean section was performed more often in this study $(28.3 \%)$ than in the Dutch general population $(6.5 \%) .{ }^{23}$ This is in accordance with Zuber and colleagues ${ }^{24}$ and the high rate of caesarean section probably reflects caution or fear on the part of obstetricians and cardiologists.
In this retrospective study only patients from tertiary centres were enrolled. This may have resulted in a selection bias; patients with severe complications or complaints are probably more likely to visit a tertiary than a secondary centre. There were no maternal deaths in this group. This may well be due to selection bias because patients enrolled in the CONCOR database since 2001 took part in this study. Therefore, patients who died during pregnancy before 2001 could not be included.

\section{Conclusion}

Because no serious complications are described in the literature, it is generally accepted that almost all women with a corrected tetralogy of Fallot can lead their lives without restrictions and that pregnancy is well tolerated. ${ }^{9}$ However, in this large cohort, complications did occur in $12 \%$ of all 50 successful pregnancies. Therefore, we advise all patients with a corrected tetralogy of Fallot to visit their cardiologist before and during pregnancy. Special attention should be paid to the severity of pulmonary regurgitation. Pulmonary valve replacement before pregnancy may be considered for patients with severe pulmonary regurgitation.

\section{Authors' affiliations}

J M Meijer, P G Pieper, W Drenthen, A A Voors, D J van Veldhuisen, Department of Cardiology of the University Hospital Groningen, Groningen, the Netherlands

T Ebels, Department of Thoracic Surgery of the University Hospital Groningen, Groningen, the Netherlands

J W Roos-Hesselink, Department of Cardiology of the Erasmus Medical Centre, Rotterdam, the Netherlands

A P J van Dijk, Department of Cardiology of the University Medical Centre Radboud, Nijmegen, the Netherlands

B J M Mulder, Department of Cardiology of the Academic Medical Centre, Amsterdam, the Netherlands

This report is part of the ZAHARA study, which is supported by a grant (2002 B1 25) to Dr P G Pieper from the Netherlands Heart Foundation.

\section{REFERENCES}

1 Therrien J, Marx GR, Gatzoulis MA. Late problems in tetralogy of Fallot: recognition, management, and prevention. Cardiol Clin 2002;20:395-404.

2 Murphy JG, Gersh BJ, Mair DD, et al. Long-term outcome in patients undergoing surgical repair of tetralogy of Fallot. N Engl J Med 1993:329:593-9.

3 Nollert G, Fischlein T, Bouterwek S, et al. Long-term survival in patients with repair of tetralogy of Fallot: 36-year follow-up of 490 survivors of the first year after surgical repair. J Am Coll Cardiol 1997:30:1374-83

4 Roos-Hesselink J, Perlroth MG, McGhie J, et al. Atrial arrhythmias in adults after repair of tetralogy of Fallot: correlations with clinical, exercise, and echocardiographic findings. Circulation 1995;91:2214-9.

5 Meijboom F, Szatmari A, Deckers JW, et al. Cardiac status and healthrelated quality of life in the long term after surgical repair of tetralogy of Fallot in infancy and childhood. J Thorac Cardiovasc Surg 1995;110:883-91.

6 Siu SC, Colman JM. Heart disease and pregnancy. Heart 2001;85:710-5.

7 Clark SL, Cotton DB, Lee W, et al. Central hemodynamic assessment of normal term pregnancy. Am J Obstet Gynecol 1989;161:1439-42.

8 Duvekot JJ, Peeters LL. Maternal cardiovascular hemodynamic adaptation to pregnancy. Obstet Gynecol Surv 1994:49(suppl 12):S1-14.

9 Thilen U, Olsson SB. Pregnancy and heart disease: a review. Eur J Obstet Gynecol Reprod Biol 1997;75:43-50.

10 Singh H, Bolton PJ, Oakley CM. Pregnancy after surgical correction of tetralogy of Fallot. BMJ (Clin Res Ed) 1982;285:168-70.

11 Nissenkorn A, Friedman S, Schonfeld A, et al. Fetomaternal outcome in pregnancies after total correction of the tetralogy of Fallot. Int Surg 1984;69:125-8.

12 Hidaka $Y$, Akagi T, Himeno W, et al. Left ventricular performance during pregnancy in patients with repaired tetralogy of Fallot: prospective evaluation using the Tei index. Circ J 2003;67:682-6.

13 Lewis BS, Rogers NM, Gotsman MS. Successful pregnancy after repair of Fallot's tetralogy. S Afr Med J 1972;46:934-6.

14 Lo TF, Tan NC. Fallot's tetralogy and pregnancy: a report of a successful pregnancy after complete correction. Med J Aust 1971;2:141-5.

15 Nunley WC Jr, Kolp LA, Dabinett LN, et al. Subsequent fertility in women who undergo cardiac surgery. Am J Obstet Gynecol 1989;161:573-6. 
16 Central Bureau of Statistics. Department of Population Statistics. Fertility in the Netherlands. Integration 1992;32:28-31.

17 Nielsen S, Hahlin M. Expectant management of first-trimester spontaneous abortion. Lancet 1995;345:84-6.

18 Nora JJ, Berg $\mathrm{K}$, Nora AH. Congenital heart disease: genetics. In: Motulsky AG, Brobow M, Harper PS, et al. Cardiovascular diseases: genetics, epidemiology and prevention, Oxford monograph on medical genetics, no 22. New York: Oxford University Press, 1991

19 Burn J, Brennan P, Little J, et al. Recurrence risks in offspring of adults with major heart defects: results from first cohort of British collaborative study. Lancet 1998;351:311-6.
20 Zellers TM, Driscoll DJ, Michels VV. Prevalence of significant congenital heart defects in children of parents with Fallot's tetralogy. Am J Cardiol 1990;65:523-6.

21 Hyett J, Moscoso G, Nicolaides K. Abnormalities of the heart and great arteries in first trimester chromosomally abnormal fetuses. Am J Med Genet 1997:69:207-16.

22 Bais JM, van der Borden DM, Pel M, et al. Vaginal birth after caesarean section in a population with a low overall caesarean section rate. Eur J Obstet Gynecol Reprod Biol 2001;96:158-62.

23 Zuber M, Gautschi N, Oechslin E, et al. Outcome of pregnancy in women with congenital shunt lesions. Heart 1999;81:271-5.

\section{IMAGES IN CARDIOLOGY}

\section{Chest $x$ rays illustrating successful resynchronisation therapy}

A 52 year old man with idiopathic dilated cardiomyopathy and a longstanding history of heart failure refractory to optimal medical treatment (New York Heart Association (NYHA) functional class III-IV) was referred to our cardiology department for implantation of an atrial synchronised biventricular pacemaker (cardiac resynchronisation therapy). At the time of observation, the patient complained of dyspnoea and asthenia following minimal effort. A third heart sound with mild apical systolic murmur, diffuse rales, bronchial wheezing, and modest signs of bilateral hydrothorax were detected at physical examination. An echocardiogram showed a notably dilated left ventricle (end diastolic diameter $84 \mathrm{~mm}$ ), with global hypokinesia in the absence of pericardial effusion. The pre-procedural chest $x$ ray is presented in panel A. After the implantation, the patient continued to assume his usual pharmacological treatment. At one month follow up, symptoms of heart failure were notably improved (from NYHA class IV to II), and physical examination was normal except for mild and inconstant right sided pleural bruits. The chest $x$ ray showed a dramatic resolution of pulmonary congestive signs and a significant reduction in radiographic heart size (panel B), while echocardiography showed a reduction in left ventricular diameter (end diastolic diameter $79 \mathrm{~mm}$ ).

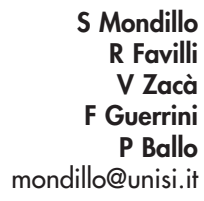

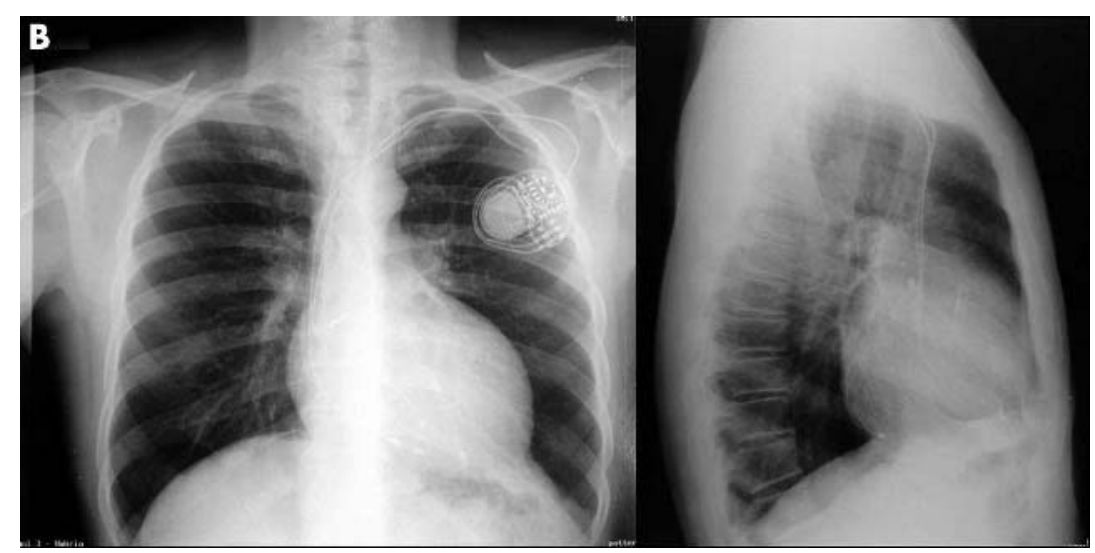

